\title{
Depression, anxiety and stress among medical and non- medical students in Saudi Arabia: An epidemiological comparative cross-sectional study
}

Ahmad A. Mirza, MBBS, MSc, Waleed A. Milaat, MD, PhD, Iman K. Ramadan, MBBS, PhD, Mukhtiar Baig, PhD, MHPE, Soha A. Elmorsy, MD, PhD, Ghada M. Beyari, MBBS, Mohammed A. Halawani, MBBS, Ruqayyah A. Azab, Medical student, Meshari T. Zahrani, Medical student, Nora K. Khayat, Medical student.

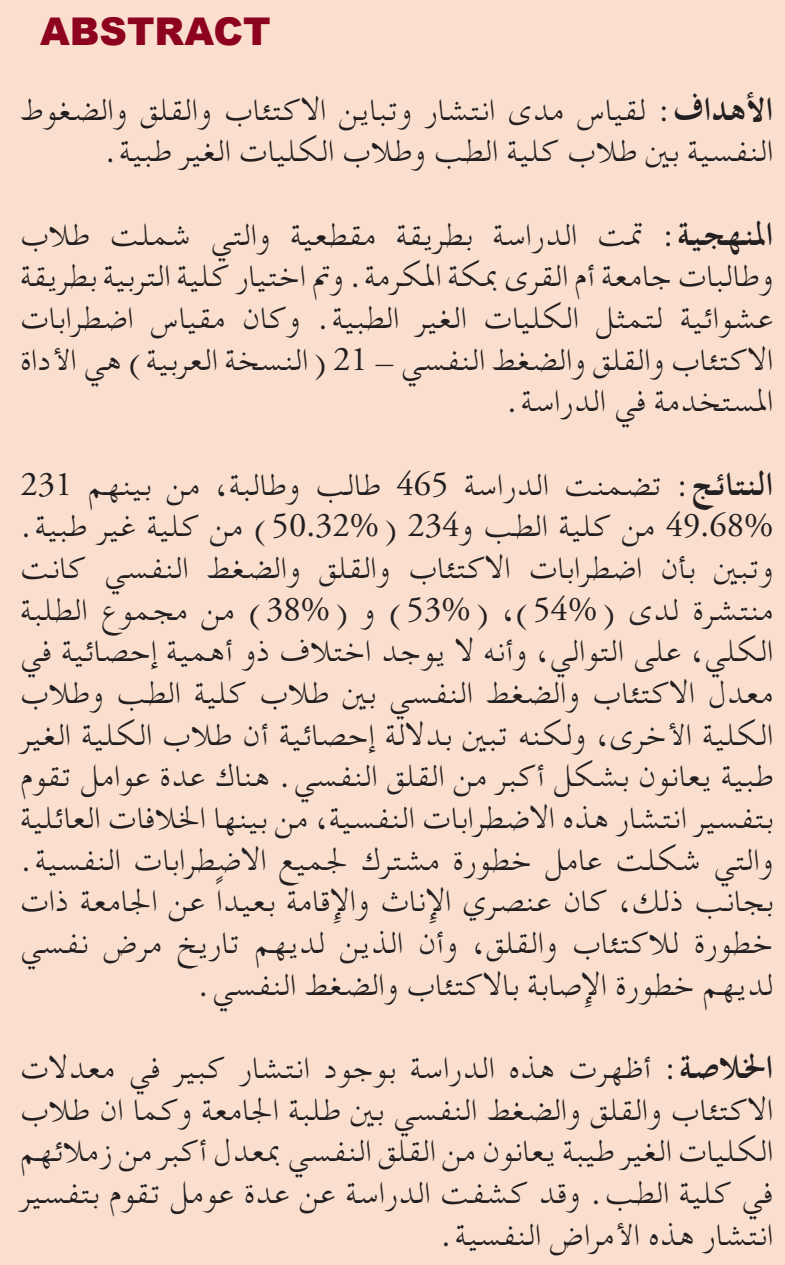

Objectives: To quantify the extent and variation of depression, anxiety and stress among medical and non-medical Saudi Arabian students.

Methods: In this cross-sectional study, students from Umm Al-Qura University, Makkah, Saudi Arabia, were recruited. The Faculty of Education was randomly selected to represent the non-medical colleges. The depression, anxiety and stress scale- 21 items (DASS-21) was used to estimate the study outcomes.

Results: Of the 465 undergraduates recruited in this study, $49.68 \% \quad(n=231)$ were medical students and $50.32 \%(\mathrm{n}=234)$ were non-medical students. Approximately 54\%, 53\%, and 38\% of the participants were found to be suffering from depression, anxiety, and stress, respectively. The analyses showed that the two groups did not differ significantly with respect to stress and depression ( $p=0.934$ and 0.423 , respectively). However, the non-medical students exhibited a significantly higher anxiety score compared to the medical students $(p=0.002)$. Family conflicts was a common risk factor for the studied psychological disturbances. Female gender and travel time from home to university were significant predictors of depression and anxiety, whereas a positive history of a psychological condition increased the likelihood of depression and stress.

Conclusion: There was a high prevalence of anxiety, stress, and depression among the students, with a significantly higher anxiety levels among the nonmedical students.

\section{Neurosciences 2021; Vol. 26 (2): 141-151 doi: 10.17712/nsj.2021.2.20200127}

From the Department of Otolarynology, Head and Neck Surgery (Mirza), Faculty of Medicine in Rabigh, from the Department of Community Medicine (Milaat, Ramadan), from the Department of Clinical Biochemistry/Medical Education (Baig), Faculty of Medicine, Rabigh, King Abdulaziz University, Jeddah, from the Department of Epidemiology and Statistics (Elmorsy), King Abdullah Medical City, Makkah, from the Faculty of Medicine (Beyari, Halawanim, Azab, Zahrani, Khayat) Umm Al-Qura University, Makkah, Kingdom of Saudi Arabia, from the Department of Community Medicine (Ramadan), Faculty of Medicine, Alazhar University, and from the Department of Pharmacology (Elmorsy), Faculty of Medicine, Cairo University, Cairo, Egypt

\section{Received 16th August 2020. Accepted 19th October2020.}

Address correspondence and reprint request to: Dr. Ahmad A. Mirza, Department of Otolaryngology, Head and Neck Surgery, Faculty of Medicine in Rabigh, King Abdulaziz University, Jeddah, Kingdom of Saudi Arabia. E-mail: aamirzal@kau.edu.sa

ORCID ID: https://orcid.org/0000-0001-6035-9566 
$\mathrm{T}$ here is a high prevalence of depression, anxiety and stress disorders (DASD) across the world. A previous report stated that around $4.4 \%$ (over 300 million) and $3.6 \%$ (264 million) of the global population suffers from depression and anxiety, respectively. Between 2005 and 2015 alone, there was a $14.9 \%$ increase in the incidence of anxiety. This report also considered depression as one of the major determinants of years lived with disability (YLD) and anxiety as a primary contributor of non-fatal health loss. ${ }^{1,2}$ Another national-level survey reported $34.8 \%$ population to be suffering from stress, of which only $2 \%$ attained medical assistance. ${ }^{3,4}$

The amount of pressure faced by the university students might lead to a considerable psychological stress, which, in turn, leads to serious mental disorders, including anxiety, stress, and depression. Over time, the academic pressure may lead to worsening of the mental health and physical wellbeing of the students, which can only be detected at advanced stages. Certain studies on medical school graduates reported an association between the psychological stress among these students and suboptimal patient care. ${ }^{5,6}$

Several studies have evaluated and compared the anxiety, stress, and depression levels of non-medical and medical students. ${ }^{7-11}$ A previous study in Saudi Arabia reported significantly lower depression rates among the medical students $(37 \%)$ compared to non-medical students $(60 \%) .^{7}$ Contrarily, a meta-analysis reported no significant differences in the prevalence of depression between non-medical and medical students. ${ }^{8}$ A systemic review demonstrated significantly higher anxiety among medical students compared to general population. ${ }^{12}$ Previous studies in Saudi Arabia also reported significantly high anxiety levels and low wellbeing of medical students. ${ }^{13,14}$ Similar to anxiety and depression, the level of stress among medical students, in the same region, was as high as 59\%, and was more prevalent among female and junior students. ${ }^{15,16}$

Several English scales have previously been used to assess the DASD prevalence in local population of Saudi Arabia, $, 73,17,18$ and a number of local studies conducted on medical students exhibited certain methodological weaknesses, such as inadequate sampling. ${ }^{19-21}$ Therefore, our aim was comparison of the DASD levels between medical and non-medical students with an adequate sampling method and by utilizing an Arabic validated

Disclosure. Authors have no conflict of interests, and the work was not supported or funded by any drug company. tool that is more understandable in our culture, and to investigate risk factors for DASD among this population.

Methods. Study design and participants. In this cross-sectional study, the medical and non-medical undergraduate students of Umm Al-Qura University (UQU), Makkah, Saudi Arabia, who enrolled in the second semester of academic year 2019, were recruited. An ethical approval was obtained from the Research Ethical Committee of Faculty of Medicine at UQU (Approval No. HAPO-02-K-012-2018-12-290), and the study was carried out in accordance with the Declaration of Helsinki principles. A total of 1317 medical students (subpopulation 1) from 2nd to 6th years were targeted in this study (female: 657, male: 660). For subpopulation 2, a total of 1109 non-medical students (female: 689, male: 420), who enrolled in the 4 years program of College of Education were targeted. The College of Education was selected among the 13 non-medical colleges by a simple random technique.

Sample size determination. On the basis of previous investigations that assessed the stress levels in medical (P1: 53\%) and non-medical students (P2: 38\%), ${ }^{22-24}$ we used two-sample comparison of proportions to determine the target sample size that can be used for the estimation of significant differences between P1 and $\mathrm{P} 2$ with a margin of error of 0.05 , confidence interval of $95 \%$, and statistical power of $80 \%$. For each subpopulation, the target sample size was determined to be 185 . However, we set the target size as $25 \%$ over the calculated sample size to compensate for the incomplete and missing questionnaires and non-responses. Hence, for this study, the target sample size was set to be 463, which was further rounded off to 465 .

Sampling technique. In this study, multistage stratified sampling technique was used with proportional allocation for the distribution of the participants on the basis of academic year and gender in each respective college. First, the calculated sample size was equally divided to include students from the 2 colleges. Then, the students were stratified first on the basis of gender and then on the basis of academic year.

Data collection. The data was collected at the beginning of the semester (January 2019), but prior to the exams, to ensure elimination of a potential stress confounder. With the help of senior students, a data collector team approached the target students. They informed the target students regarding the study objectives. All the target students were assured of their anonymity and confidentiality. All the students participated voluntarily and could withdraw from the 
study at any time. All the students who declined to participate or submitted incomplete response to the core part of the survey (i.e. outcomes measurement) were excluded from the study sample.

Questionnaire. The survey questionnaire was divided into 2 parts. The first part focused on the sociodemographic characteristics, medical status, lifestyle, and academic profiles. The second part measured the stress, anxiety, and depression levels among the students.

The sociodemographic information consisted of gender, age, marital status, either or not having children, monthly income of family, place of residence during study period, hometown, father's educational level, mother's educational level, status of the parents (alive and married/divorced or dead), family responsibilities, family conflicts, travel time from home to university, and whether working during the study period.

The information regarding the academic profile included field of study, academic year, grade point average (GPA; range: $0-4$ ), number of registered weekly hours, study hours per day after school, whether study field matches the first choice at the time of admission, and failure in one or more learning modules.

Information related to medical status consisted of history of psychiatric condition, history of chronic diseases, psychiatric follow-up, and use of any type of medication regularly. Information regarding lifestyle factors consisted of current smoking status, consumption level of tea and coffee, consumption levels of energy beverages, frequency of physical exercise, eating habits (unhealthy to very healthy), sleep quantity (average hours of sleep) and quality (poor to good), involvement in leisure activities and hobbies (none to regularly), compliance with religious duties (poor to good), and frequency of smart devise use for entertainment.

The depression, anxiety and stress scale (DASS) was used for the measurement of the psychological morbidities. The original DASS questionnaire consisted of 42 items. However, a shorter validated 21-item DASS version is more widely used. Of the 21 items, 7 items belong to each of the depression, anxiety, and stress domains. The responses for each item ranged from 0 to 3, with the minimum score (0) indicating that the item does not apply to the student at all and the maximum score (3) indicating that the item applies totally or frequently to the student. ${ }^{25}$ The scores of each subscale were the sums of the individual scores of the related items. Each subscale score was then multiplied by $2(21 \times 2=42)$ and evaluated on the basis of severity rating index. The DASS-21 has previously been used for healthcare studies and have been shown to exhibit high reliability and internal consistency, with acceptable values of Cronbach's $\alpha$ (stress: 0.865, depression: 0.889, anxiety: 0.822). ${ }^{26,27}$ The diagnostic performance of the shortened version was comparable to that of the original version, with good psychometric properties. ${ }^{24-}$ 26,28 The Arabic version of the scale has already been psychometrically validated for Arab population. ${ }^{29}$ On the basis of the score, each emotional state is categorized into different categories ranging from normal to extremely severe. Higher score corresponded to more severe emotions.

Statistical analysis. Stata version 13 software (StataCorp. 2013. Stata Statistical Software: Release 13. College Station, TX: StataCorp LP) was used for statistical analyses. A new variable (academic level) was created to categorize the variable Academic year into 2 levels: Junior (students currently in the 1st, 2nd, or 3rd year of university) and senior (students currently in the 4th, 5th, or 6th year of university). The outcome categories, that is, mild, moderate, severe, and extremely severe were combined in a single category. Descriptive statistics were used to summarize the data by estimating frequency (and percentage) for categorical variables and mean ( \pm standard deviation) for continuous variables. Pearson's Chi-squared test was used to determine the significance of prevalence and severity of DASD in medical versus non-medical students, whereas Student's $\mathrm{t}$-test was used to determine the significance of DASD scores between the 2 groups of students. A multivariate binary logistic regression analysis was performed, and the variable Study field (the primary exposure variable) was retained regardless of its significance level. The remaining explanatory variables $(n=34)$ that exhibited statistical significance $(p<0.1)$ in the univariate analysis were retained for the multivariate logistic regression analysis. The multivariate logistic analysis was carried out with a backward stepwise approach, using an entry $p$-value of 0.10 and a removal $p$ value of 0.101 for variable selection. $P$-values $<0.05$ were considered as statistically significant.

Results. Descriptive analysis. Four hundred and sixty-five undergraduate students were recruited for this study, of which 234 (50.32\%) and 231 (49.68\%) students were non-medical and medical students, respectively. Mean ages of non-medical and medical students were $21.23 \pm 2.34$ years and $21.67 \pm 1.56$ years, respectively. Around $57 \%$ of the participants were female. About $91 \%$ of the participants were unmarried, 
DASD in medical vs. non-medical students ... Mirza et al

Table 1 - Socio-demographic characteristics and academic profile of the study participants.

\begin{tabular}{|c|c|c|c|}
\hline & Medical Students $n=231$ & $\begin{array}{l}\text { Non-medical Students } n=234 \\
n(\%)\end{array}$ & Total $n=465$ \\
\hline \multicolumn{4}{|l|}{ Socio-demographic characteristics } \\
\hline Age (mean, SD) & $21.67(1.56)$ & $21.23(2.34)$ & $21.46(2.00)$ \\
\hline \multicolumn{4}{|l|}{ Gender } \\
\hline Male & $106(45.89)$ & $92(39.32)$ & $198(42.58)$ \\
\hline Female & $125(54.11)$ & $142(60.68)$ & $267(57.42)$ \\
\hline \multicolumn{4}{|l|}{ Marital status } \\
\hline Not married & $224(96.97)$ & $202(86.32)$ & $426(91.61)$ \\
\hline Married & $7(3.03)$ & $32(13.68)$ & $39(8.39)$ \\
\hline \multicolumn{4}{|l|}{ Hometown ${ }^{*}$} \\
\hline Urban & $224(96.97)$ & $210(91.30)$ & $234(94.14)$ \\
\hline Rural/Countryside & $7(3.03)$ & $20(8.70)$ & $27(5.86)$ \\
\hline \multicolumn{4}{|l|}{ Father's educational level } \\
\hline Illiterate & $2(0.87)$ & $8(3.46)$ & $10(2.17)$ \\
\hline Primary-intermediate & $28(12.17)$ & $53(22.94)$ & $81(17.57)$ \\
\hline Secondary & $62(26.96)$ & $70(30.30)$ & $132(28.63)$ \\
\hline University+ & $138(60.00)$ & $100(43.29)$ & $238(51.63)$ \\
\hline \multicolumn{4}{|l|}{ Mother's educational level' } \\
\hline Illiterate & $9(3.90)$ & $30(12.99)$ & $39(8.44)$ \\
\hline Primary-intermediate & $29(12.55)$ & $52(22.51)$ & $81(17.53)$ \\
\hline Secondary & $45(19.48)$ & $59(25.54)$ & $104(22.51)$ \\
\hline University+ & $148(64.07)$ & $90(38.96)$ & $238(51.52)$ \\
\hline \multicolumn{4}{|l|}{ Residence place during the time of the study ${ }^{*}$} \\
\hline Students' residence facility & $9(3.90)$ & $15(6.55)$ & $24(5.22)$ \\
\hline Living with family & $222(96.10)$ & $214(93.45)$ & $436(94.78)$ \\
\hline \multicolumn{4}{|l|}{ Family monthly income (in Saudi Riyals)* } \\
\hline$<5000$ & $6(3.55)$ & $27(17.53)$ & $33(10.22)$ \\
\hline $5000-10000$ & $32(18.93)$ & $42(27.27)$ & $74(22.91)$ \\
\hline$>10000-20000$ & $74(43.79)$ & $62(40.26)$ & $136(42.11)$ \\
\hline$>20000$ & $57(33.73)$ & $23(14.94)$ & $80(24.77)$ \\
\hline \multicolumn{4}{|l|}{ Academic profile } \\
\hline Number of registered weekly hours (mean, SD) ${ }^{*}$ & $25.64(9.35)$ & $16.28(4.39)$ & $20.79(8.60)$ \\
\hline \multicolumn{4}{|l|}{ Academic level } \\
\hline Junior & $89(38.53)$ & $168(78.50)$ & $257(57.75)$ \\
\hline Senior & $142(61.47)$ & $46(21.50)$ & $188(42.25)$ \\
\hline \multicolumn{4}{|l|}{ Did you match with the first choice in admission?* } \\
\hline Yes & $197(86.40)$ & $140(61.50)$ & $337(74.07)$ \\
\hline No & $31(13.60)$ & $87(38.50)$ & $118(25.93)$ \\
\hline \multicolumn{4}{|l|}{ Failure in learning module $(s)^{*}$} \\
\hline No & $217(94.76)$ & $156(67.24)$ & $373(80.91)$ \\
\hline Yes & $12(5.24)$ & $76(32.76)$ & $88(19.09)$ \\
\hline $\mathrm{GPA}($ mean, SD)* & $3.39(0.44)$ & $3.05(0.63)$ & $3.23(0.56)$ \\
\hline \multicolumn{4}{|l|}{ Daily studying hours after school } \\
\hline$<1$ hour & $21(9.09)$ & $78(33.91)$ & $99(21.48)$ \\
\hline $1-2$ hours & $86(37.23)$ & $83(36.09)$ & $169(36.66)$ \\
\hline$>2-4$ hours & $90(38.96)$ & $41(17.83)$ & $131(28.42)$ \\
\hline$>4$ hours & $34(14.72)$ & $28(12.17)$ & $62(13.45)$ \\
\hline & e variable has missing valu & & \\
\hline
\end{tabular}


Table 2 - Depression, anxiety and stress disorders among medical and non-medical students

\begin{tabular}{lccc}
\hline Category & Medical students & Non-medical students & $P$-value ${ }^{\ddagger}$ \\
\hline Depression & & & \\
Prevalence & $129(55.84 \%)$ & $122(52.14 \%)$ & 0.423 \\
Mean of score (SD) & $12.94(11.29)$ & $11.24(9.72)$ & $0.082^{\S}$ \\
Normal & $102(44.16)$ & $112(47.86)$ & \\
Mild & $29(12.55)$ & $31(13.25)$ & 0.142 \\
Moderate & $50(21.65)$ & $48(20.51)$ & \\
Severe & $20(8.66)$ & $28(11.97)$ & \\
Extremely severe & $30(12.99)$ & $15(6.41)$ & \\
Anxiety & & & \\
Prevalence & $106(45.89 \%)$ & $141(60.26 \%)$ & $0.002^{*}$ \\
Mean (SD) & $8.46(9.07)$ & $11.09(9.79)$ & $0.003^{*}$ \\
Normal & $126(54.11)$ & $93(39.74)$ & \\
Mild & $20(8.66)$ & $23(9.83)$ & $0.024^{*}$ \\
Moderate & $39(16.88)$ & $44(18.80)$ & \\
Severe & $16(6.93)$ & $26(11.11)$ & \\
Extremely severe & $31(13.42)$ & $48(20.51)$ & \\
Stress & & & \\
Prevalence & $87(37.66 \%)$ & $89(38.03 \%)$ & \\
Mean (SD) & $13.74(11.69)$ & $12.09(10.23)$ & \\
Normal & $144(62.34)$ & $145(61.97)$ & \\
Mild & $18(7.79)$ & $24(10.26)$ & \\
Moderate & $26(11.26)$ & $33(14.10)$ & $0.007^{*}$ \\
Severe & $17(7.36)$ & $25(10.68)$ & \\
Extremely severe & $26(11.26)$ & $7(2.99)$ & \\
\hline${ }^{*}$ Statically significant at $p<0.05 .{ }^{\ddagger}$ Chi-squared test unless mentioned otherwise. ${ }^{\S}$ Student’s t-test. \\
\hline
\end{tabular}

with a higher proportion of medical students married compared to the non-medical students. Around 94\% participants were raised in urban regions. The number of registered weekly hours varied across the study samples, with medical students exhibiting longer university hours. Higher proportion of medical students matched their first choice than the non-medical students. A lower proportion of medical students failed in learning modules compared to the non-medical students. The sociodemographic characteristics and academic profiles of the participants are listed in Table 1 .

$D A S D$ prevalence. We observed a high DASD prevalence among the participants. Overall, over 50\% of the participants exhibited depression, with $10 \%$ of the participants suffering from extreme depression. Similarly, 53\% of the participants exhibited anxiety, with $17 \%$ of the participants suffering from extreme anxiety. Furthermore, $38 \%$ of the participants suffered from psychological stress. The DASD prevalence among the study sample is depicted in Figures 1 and 2 and Table 2. While comparing between both the groups, we observed comparable mean scores of depression and stress ( $p=0.082$ and $p=0.105$, respectively). Similarly, we did not observe significant differences between the prevalence of depression and stress $(p=0.423$ and $9=$ 0.934 , respectively). On the contrary, mean anxiety scores and anxiety prevalence of both the groups were significantly different $(p=0.003$ and $p=0.002$, respectively). Of the 2 groups, the non-medical students exhibited higher anxiety levels.

$D A S D$-associated factors. We conducted multivariate binary logistic analyses to determine the factors that were independently associated with depression, anxiety, and stress (Tables 3, 4, and 5, respectively).

Depression. Our results showed that depression was not associated with the field of study. However, female gender, history of psychiatric disorder, senior academic year, travel time from home to university, and family conflicts at home were significantly associated with depression. The strongest association was observed for history of psychiatric disorders (aOR: 10.66, 95\% CI: 1.32-86.38).

Anxiety. We observed that non-medical field, female gender, high consumption of energy drinks, spending 
Table 3 - Univariate and multivariate logistic regression analysis of different factors on depression among medical and non-medical students.

\begin{tabular}{|c|c|c|c|c|c|c|c|c|}
\hline \multirow[t]{2}{*}{ Variables } & \multirow[t]{2}{*}{ OR } & \multirow[t]{2}{*}{ P value } & \multicolumn{2}{|c|}{$95 \% \mathrm{CI}$} & \multirow[t]{2}{*}{$\mathrm{aOR}$} & \multirow[t]{2}{*}{$P$ value } & \multicolumn{2}{|c|}{$95 \% \mathrm{CI}$} \\
\hline & & & UL & LL & & & $\mathrm{LL}$ & UL \\
\hline \multicolumn{9}{|l|}{ Study field } \\
\hline Medicine & Ref & & & & Ref & & & \\
\hline Education & 0.86 & 0.42 & 0.60 & 1.24 & 1.07 & 0.84 & 0.55 & 2.07 \\
\hline Energy beverages $^{\dagger}$ & 1.43 & $0.01^{*}$ & 1.08 & 1.89 & 1.61 & 0.05 & 1.01 & 2.58 \\
\hline \multicolumn{9}{|l|}{ Gender } \\
\hline Male & Ref & & & & Ref & & & \\
\hline Female & 1.89 & $<0.001^{*}$ & 1.30 & 2.74 & 2.13 & $0.02^{*}$ & 1.15 & 3.93 \\
\hline Family conflicts at home $e^{\ddagger}$ & 2.10 & $<0.001^{*}$ & 1.45 & 3.04 & 1.83 & $0.04^{*}$ & 1.02 & 3.26 \\
\hline \multicolumn{9}{|l|}{ Psychiatric condition } \\
\hline No & Ref & & & & Ref & & & \\
\hline Yes & 7.43 & $<0.001^{*}$ & 2.58 & 21.41 & 10.66 & $0.03^{*}$ & 1.32 & 86.38 \\
\hline Time from home to university ${ }^{\S}$ & 1.53 & $<0.001^{*}$ & 1.19 & 1.96 & 1.50 & $0.04^{*}$ & 1.02 & 2.19 \\
\hline \multicolumn{9}{|l|}{ Academic level } \\
\hline Junior & Ref & & & & Ref & & & \\
\hline Senior & 1.29 & 0.19 & 0.88 & 1.88 & 2.53 & $0.01^{*}$ & 1.29 & 4.95 \\
\hline $\begin{array}{r}\text { OR - Odds ratio, aOR - adjuste } \\
\text { significant. }{ }^{\dagger} \text { Ordinal variable } \\
\text { Composed/Stable, } 2: \text { Minor co } \\
\text { minutes }\end{array}$ & $\begin{array}{l}\text { dds rat } \\
\text { Never, } \\
\text { icts, an } \\
\text { more t }\end{array}$ & $\begin{array}{l}\text { CI - confic } \\
\text { ccasionall } \\
\text { Major co } \\
30-60 n\end{array}$ & $\begin{array}{l}\text { ce inte } \\
\text { 3: Onc } \\
\text { icts). }{ }^{s} \\
\text { lutes, a }\end{array}$ & $\begin{array}{l}\text { 1, UL - I } \\
\text { aily, and } \\
\text { linal var } \\
4: \text { more }\end{array}$ & $\begin{array}{l}\text { per } \lim \\
: \geq 2 \text { tim } \\
\text { le }(1: \text { le } \\
\tan 60 \mathrm{n}\end{array}$ & $\begin{array}{l}\text { LL - Lo } \\
\text { s daily). }{ }^{\ddagger} \\
\text { s than } 15 \\
\text { inutes). }\end{array}$ & $\begin{array}{l}\text { r limi } \\
\text { rdinal } \\
\text { inutes }\end{array}$ & $\begin{array}{l}\text { atistically } \\
\text { able }(1: \\
15-30\end{array}$ \\
\hline
\end{tabular}

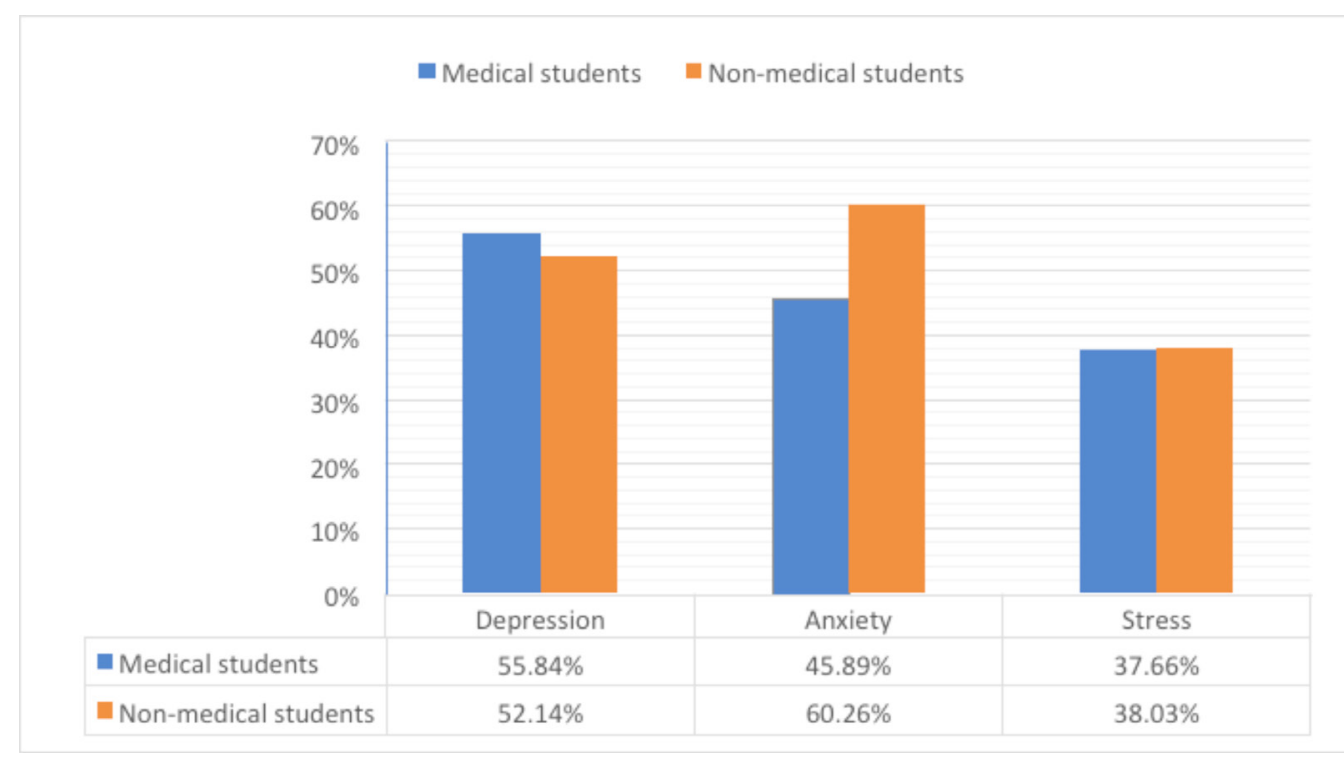

Figure 1 - Bar chart demonstrating the prevalence of depression, anxiety and stress disorders (DASD) among medical and non-medical students

more time in leisure activities and hobbies, long travel time from home to university, and family conflicts were significantly associated with anxiety. The strongest association was observed for non-medical field (aOR: 2.07, $p=0.02)$.
Stress. The generated model showed no significant difference in the comorbidity of stress between the medical and non-medical students. An association was found for the parent status, i.e. students whose parents were married and alive had a lower chance 
DASD in medical vs. non-medical students ... Mirza et al
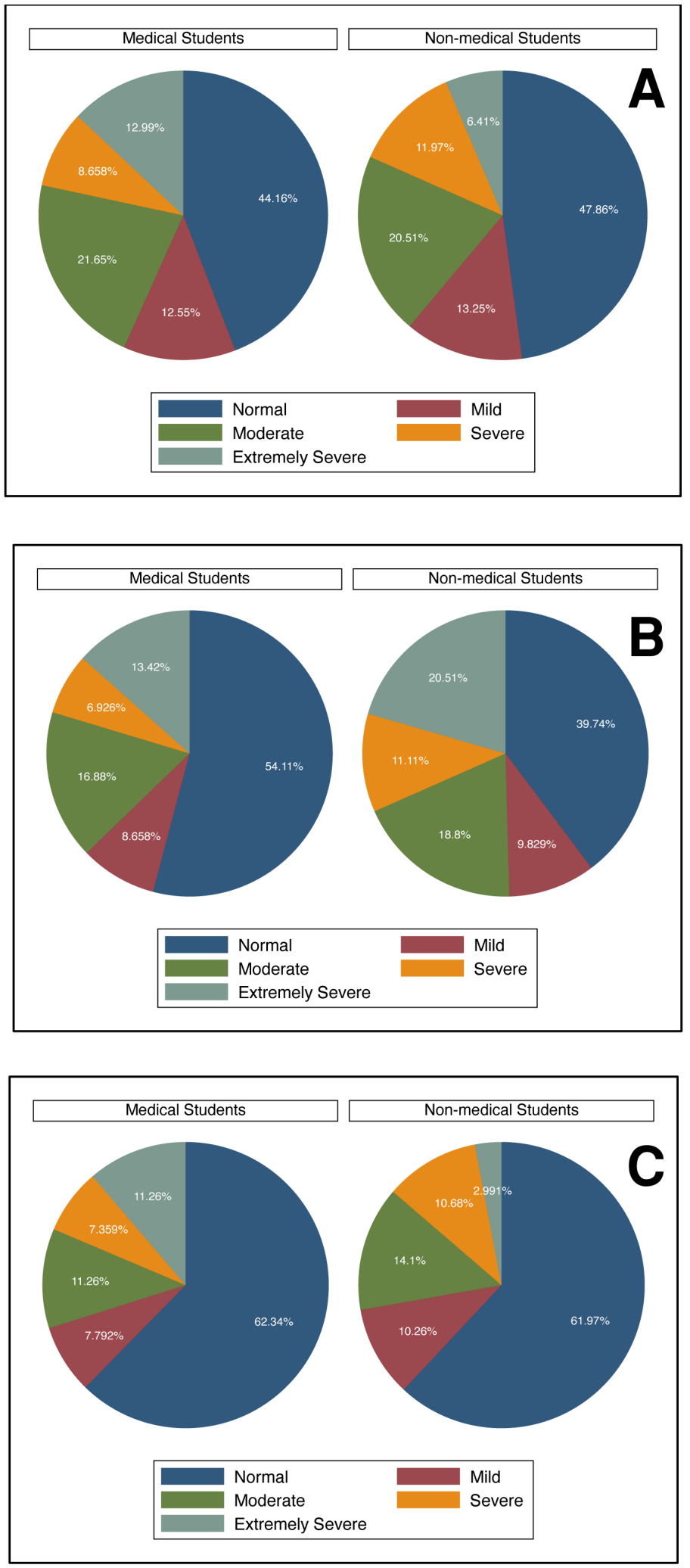

Figure 2 - Pie chart illustrating a)the depression severity in medical versus non-medical students, b) the anxiety severity in medical versus non-medical students, C) the stress severity in medical versus non-medical students. 
Table 4 - Univariate and multivariate logistic regression analysis of different factors on anxiety among medical and non-medical students.

\begin{tabular}{|c|c|c|c|c|c|c|c|c|}
\hline \multirow[t]{2}{*}{ Category } & \multirow[t]{2}{*}{ OR } & \multirow[t]{2}{*}{ P-value } & \multicolumn{2}{|c|}{$95 \% \mathrm{CI}$} & \multirow[t]{2}{*}{$\mathrm{aOR}$} & \multirow[t]{2}{*}{ P-value } & \multicolumn{2}{|c|}{$95 \% \mathrm{CI}$} \\
\hline & & & UL & LL & & & $\mathrm{LL}$ & UL \\
\hline \multicolumn{9}{|l|}{ Study field } \\
\hline Medicine & Ref & & & & Ref & & & \\
\hline Education & 1.79 & $0.002^{*}$ & 1.24 & 2.58 & 2.07 & $0.02^{*}$ & 1.15 & 3.71 \\
\hline Hobbies and leisure $^{\dagger}$ & 1.00 & 0.99 & 0.82 & 1.22 & 1.40 & $0.04^{*}$ & 1.02 & 1.93 \\
\hline \multicolumn{9}{|l|}{ Gender } \\
\hline Male & Ref & & & & Ref & & & \\
\hline Female & 2.13 & $<0.001^{*}$ & 1.46 & 3.09 & 1.97 & $0.03^{*}$ & 1.07 & 3.61 \\
\hline Family conflicts at home ${ }^{\ddagger}$ & 2.21 & $<0.001^{*}$ & 1.53 & 3.20 & 1.95 & $0.02^{*}$ & 1.12 & 3.40 \\
\hline Energy beverages $s^{\S}$ & 1.66 & $0.001^{*}$ & 1.24 & 2.21 & 1.77 & $0.02^{*}$ & 1.10 & 2.84 \\
\hline Time from home to universitys & 1.74 & $<0.001^{*}$ & 1.35 & 2.24 & 1.68 & $0.01^{*}$ & 1.14 & 2.47 \\
\hline \multicolumn{9}{|c|}{$\begin{array}{l}\text { OR - Odds ratio, aOR - adjusted odds ratio, CI - confidence interval, UL - Upper limit, LL - Lower limit, }{ }^{*} \text { statistically } \\
\text { significant, }{ }^{\dagger} \text { Ordinal variable (1: None, } 2: \text { Rarely, 3: Occasionally, and 4: Regularly). }{ }^{\ddagger} \text { Ordinal variable (1: Composed/Stable, } \\
\text { 2: Minor conflicts, and 3: Major conflicts). }{ }^{\circledR} \text { Ordinal variable (1: Never, } 2: \text { Occasionally, 3: Once daily, and } 4: \geq 2 \text { times daily) } \\
\text { 'Ordinal variable (1: less than } 15 \text { minutes, } 2: 15-30 \text { minutes, 3: more than } 30-60 \text { minutes, and 4: more than } 60 \text { minutes) }\end{array}$} \\
\hline
\end{tabular}

Table 5 - Univariate and multivariate logistic regression analysis of different factors on stress among medical and non-medical students.

\begin{tabular}{|c|c|c|c|c|c|c|c|c|}
\hline \multirow[t]{2}{*}{ Category } & \multirow[t]{2}{*}{ OR } & \multirow[t]{2}{*}{$P$-value } & \multicolumn{2}{|c|}{$95 \% \mathrm{CI}$} & \multirow[t]{2}{*}{$\mathrm{aOR}$} & \multirow[t]{2}{*}{$P$-value } & \multicolumn{2}{|c|}{$95 \% \mathrm{CI}$} \\
\hline & & & LL & UL & & & LL & $\mathrm{UL}$ \\
\hline \multicolumn{9}{|l|}{ Study field } \\
\hline Medicine & Ref & & & & Ref & & & \\
\hline Education & 1.02 & 0.93 & 0.70 & 1.48 & 0.98 & 0.95 & 0.57 & 1.70 \\
\hline Family conflicts at home ${ }^{\dagger}$ & 3.07 & $<0.001^{*}$ & 2.12 & 4.43 & 2.69 & $<0.001^{*}$ & 1.67 & 4.33 \\
\hline \multicolumn{9}{|l|}{ Psychiatric condition } \\
\hline No & Ref & & & & Ref & & & \\
\hline Yes & 7.67 & $<0.001^{*}$ & 3.27 & 17.98 & 5.21 & $0.002^{*}$ & 1.79 & 15.14 \\
\hline Daily studying hours after school $^{\ddagger}$ & 1.32 & $0.006^{*}$ & 1.09 & 1.62 & 1.37 & $0.02^{*}$ & 1.04 & 1.79 \\
\hline Smart device use for entertainment ${ }^{\S}$ & 1.50 & $<0.001^{*}$ & 1.24 & 1.82 & 1.48 & $0.002^{*}$ & 1.15 & 1.91 \\
\hline \multicolumn{9}{|l|}{ Parent status } \\
\hline Divorced or dead & Ref & & & & Ref & & & \\
\hline Alive $\&$ married & 1.58 & $0.001^{*}$ & 1.19 & 2.10 & 0.43 & $0.008^{*}$ & 0.23 & 0.81 \\
\hline \multicolumn{9}{|l|}{ Failure in learning module(s) } \\
\hline No & Ref & & & & Ref & & & \\
\hline Yes & 0.89 & 0.53 & 0.61 & 1.29 & 2.07 & $0.04^{*}$ & 1.02 & 4.19 \\
\hline $\begin{array}{r}\text { OR - Odds ratio, aOR - adjusted od } \\
\text { significant, }{ }^{\dagger} \text { Ordinal variable }(1: \mathrm{C} \\
\text { less than } 1 \text { hour, } 2: 1-2 \text { hours, } 3: n \\
\text { hours daily, } 2: 2-4 \text { hour }\end{array}$ & $\begin{array}{l}\text { ratio, } \\
\text { posed/ } \\
\text { ee than } \\
\text { aily, } 3\end{array}$ & $\begin{array}{l}\text { confiden } \\
\text { ble, } 2 \text { : Mi } \\
\text { hours, ar } \\
\text { re than } 4\end{array}$ & $\begin{array}{l}\text { interv } \\
\text { r conf } \\
4: \text { mo } \\
\text { hours }\end{array}$ & $\begin{array}{l}\mathrm{JL}-\mathrm{U}_{\mathrm{P}} \\
\text {, and } 3 \\
\text { han } 4 \mathrm{~h} \\
\text { ly, and }\end{array}$ & $\begin{array}{l}\text { er limi } \\
\text { Major } \\
\text { urs), }{ }^{\S} \mathrm{C} \\
\text { more }\end{array}$ & $\begin{array}{l}\text { LL - Low } \\
\text { nflicts), }{ }^{\ddagger} \\
\text { dinal vari } \\
\text { an } 6 \text { hour }\end{array}$ & $\begin{array}{l}\text { limit, } \\
\text { dinal } v \\
\text { e (1: le } \\
\text { laily) }\end{array}$ & $\begin{array}{l}\text { tistically } \\
\text { ble }(1: \\
\text { han } 2\end{array}$ \\
\hline
\end{tabular}

of stress $(\mathrm{OR}=0.43, p=0.008)$. Furthermore, stress was associated with history of psychiatric disorders (OR: 5.21, $p=0.002$ ) and family conflicts (OR: 2.69, $p<0.001)$.

Discussion. The incidence of psychological stress among the students is a serious cause of concern, as it alters their behavior, affects their academics, and impacts the society as a whole. Here, we observed comparable depression levels among the non-medical $(52 \%)$ and medical students $(56 \%)$. However, the rate of depression observed among the medical students in this study was lower than that observed in a previous study involving 20 universities of Saudi Arabia. ${ }^{20}$ On 
the contrary, the depression rate in our study was higher than that observed for the Middle Eastern university students (44.4\%). ${ }^{30}$ Furthermore, we observed a $60 \%$ and $46 \%$ anxiety rates among the non-medical and medical students, respectively, in this study, which were higher than those reported in previous Saudi Arabian studies. ${ }^{17,31}$ Recently, a meta-analysis reported global anxiety rates of $29.2 \%-38.7 \%$ among the medical students, with higher anxiety levels among the Asian and Middle Eastern students. ${ }^{12}$ Several previous studies have demonstrated high stress levels among the medical, dental, and nursing students. ${ }^{32-34}$

The difference in the rate of depressive symptoms between medical and non-medical students in our study was in line with some literature ${ }^{35,36}$ that concluded no evidence supports the difference in occurrence of depression between medical and non-medical students. In addition, results of a meta-analysis demonstrated that there was not statistically difference in the rate of depression between clinical and pre-clinical students. ${ }^{37}$ However, this outcome is contrary to that of Raddadi et. al. who demonstrated higher depression prevalence in non-medical than in medical students. ${ }^{7}$ Such varied results might be attributed to differences in the study design, assessment tools, and demographic characteristics of the study population. Furthermore, our results showed higher anxiety prevalence in non-medical students. These findings were in agreement with a previous study that showed higher prevalence of psychological distress among non-medical students. ${ }^{38} \mathrm{In}$ our study, both groups of students exhibited comparable rates of stress prevalence. This finding was contrary to the results of Aamir et al who demonstrated higher stress prevalence rates among the medical students (54.6\%) than the non-medical students $(20.6 \%) .{ }^{11}$

The academic workload in the medical field is comparable across the world and is unavoidable; however, with the aid of counselors, the students can cope up with the workload and the associated pressure. ${ }^{39}$ Medical students constantly encounter several emotional and mental disturbances. In addition, they face large amounts of pressure during their carrier as they need to master a new language and to be involved in different modalities of education while spending long hours studying at home and learning at the university. In addition, they are part of a competitive environment requiring personal and social sacrifices. ${ }^{40}$ On the contrary, despite longer registered university hours, the medical students in this study exhibited lower anxiety scores. Two explanations might be responsible for this finding. First is the mentorship program that was recently launched by the UQU medical faculty, which aids the medical students in dealing with their hardships. Second is the limited number of studies that compare the anxiety levels of medical students with those of the general population including non-medical students, which might indicate the presence of yet undiscovered potential stress-causing factors among non-medical students.

The DASS is a symptom-based scale in which the participants may exaggerate or underestimate their symptoms. This might lead to biased responses to these questionnaires. We propose that future investigators must focus on using specific tools that are designed for the evaluation of this type of bias. The information regarding psychiatric morbidities provided by the DASS are comparable to that provided by Diagnostic and Statistical Manual of Mental Disorders - IV (DSM-IV). The stress domain in the DASS corresponds the general anxiety domain; thus, the stress levels that were assessed by this questionnaire do not reflect the broad range of emotional symptoms that arise due to stressful events. In clinical settings, except the general anxiety disorder, the anxiety domain of DSM-IV closely resembles that of the tool used in this study. Furthermore, the depression domain of the DASS resembles the mood disorders as defined by the DSM-IV. The emotional severity assessed by the DASS is used to label the full range of scores in the population. For instance, "mild severity" in the DASS means that an individual's score was above the mean score of the population, but not so high as to warrant any professional help. Thus, "mild severity" in DASS does not correspond to "mild state of disorder". ${ }^{25}$

Limitations and recommendations: The study results could not be generalized to the other non-medical colleges as these clusters (i.e. non-medical colleges) should be hypothetically identical for the outcomes (i.e. depression, anxiety and stress). Furthermore, we followed the design of a cross-sectional study, which might help in the assessment of severity of negative emotions but could not be used to determine causality. For the assessment of sleep quality, a single question was used instead of a validated questionnaire. Finally, we used DAS-21 questionnaire, which could be used for the screening purposes but cannot be used in place of clinical examination.

Conclusion and implications for further research: DASD are highly prevalent among undergraduate medical as well as non-medical students. With the exception of anxiety, there was no significant difference in the severity and prevalence of psychological comorbidities between medical and non-medical students. Thus, attention should be paid to students regardless of 
their field of the study, and related surveys should be carried out across all colleges. There is a need to establish community-based primary and secondary mental health prevention programs, and implementation of a mentorship program for students is highly encouraged. Moreover, regular audits should be conducted for already established programs. Universities with counseling programs should constantly determine the DASDassociated factors and try to eliminate them. Future studies considering students from other non-medical colleges are warranted.

Acknowledgements. The authors acknowledge sincerely Rasha A. Mandili, Emad A. Alzahrani, Lujain A. Alzahrani, Abdulrahman M. Alharthi, Ziyad A. Alhazmi and Talah A. Felemban, medical students at Faculty of Medicine, Umm Al-Qura University, Makkah, Saudi Arabia, for their participation in the data collection. The authors express their sincere thanks to Dr. Areej A. AlFattani, for her assistance in data preparation. We are truly grateful to Dr. Mohamed A. Haireche for the invaluable guidance and language editing. The authors extend thanks to Dr. Hammam A. Baarimah, a psychiatry physician at Makkah Healthcare Cluster, Ministry of Health, Saudi Arabia, for providing comments that helped in improving the study output.

\section{References}

1. GBD 2015 Disease and Injury Incidence and Prevalence Collaborators. Global, regional, and national incidence, prevalence, and years lived with disability for 310 diseases and injuries, 1990-2015: a systematic analysis for the Global Burden of Disease Study 2015. Lancet 2016; 388: 1545-1602.

2. World Health Organization (WHO). Depression and other common mental disorders: global health estimates. Geneva: WHO; 2017. Available from: https://www.who.int/mental_ health/management/depression/prevalence_global_health_ estimates/en/

3. Mirzaei M, Yasini Ardekani SM, Mirzaei M, Dehghani A. Prevalence of Depression, Anxiety and Stress among Adult Population: Results of Yazd Health Study. Iran J Psychiatry 2019; 14: 137-146.

4. Lykkegaard J, Rosendal M, Brask K, Brandt L, Prior A. Prevalence of persons contacting general practice for psychological stress in Denmark. Scand J Prim Health Care 2018; 36: 272-280.

5. Mareiniss DP. Decreasing GME training stress to foster residents' professionalism. Acad Med 2004; 79: 825-831.

6. Shanafelt TD, Bradley KA, Wipf JE, Back AL. Burnout and self-reported patient care in an internal medicine residency program. Ann Intern Med 2002; 136: 358-367.

7. Raddadi A, Aljabri JN, Kareem MA, Alattas AM, Alkhalawi MJ. The Prevalence of Depression and Anxiety among Medical Students in Comparison with Non-Medical Students: A Cross-Sectional Study in in Taibah University, Al Madinah Al Munawwarah, Saudi Arabia, 2016. International Journal of Academic Scientific Research 2017; 5: 2272-6446.

8. Puthran R, Zhang MW, Tam WW, Ho RC. Prevalence of depression amongst medical students: a meta-analysis. Med Educ 2016; 50: 456-468.

9. Gama Marques J. Letter to the Editor about the Article: "Still Regarding Anxiety, Depression and Academic Performance: A Study Amongst Portuguese Medical Students Versus Non-Medical Students", by João Moreira de Sousa, Cátia A. Moreira, Diogo Telles-Correia. Acta Med Port 2018; 31: 607-608.
10. Umair Jahngir M, Hassan Imam HS, Ahmad MQ, Jahangir M, Asad Fraz M, Shahid Ghaffar M. Pattern of Stress among Medical Students of Faisalabad Medical University, Faisalabad and Non-Medical Students of University of Agriculture, Faisalabad. Epidemiology (Sunnyvale) 2018; 8: 349.

11. Aamir IS. Stress Level Comparison of Medical and Nonmedical Students: A Cross Sectional Study done at Various Professional Colleges in Karachi, Pakistan. Acta Psychopathologica 2017; 3: 1-6.

12. Quek TT, Tam WW, Tran BX, Zhang M, Zhang Z, Ho CS, et al. The Global Prevalence of Anxiety Among Medical Students: A Meta-Analysis. Int J Environ Res Public Health 2019; 16: 2735 .

13. Kulsoom B, Afsar NA. Stress, anxiety, and depression among medical students in a multiethnic setting. Neuropsychiatr Dis Treat 2015; 11: 1713-1722.

14. Aboalshamat K, Hou XY, Strodl E. Psychological well-being status among medical and dental students in Makkah, Saudi Arabia: a cross-sectional study. Med Teach 2015; 37: S75-S81.

15. Gazzaz ZJ, Baig M, Al Alhendi BSM, Al Suliman MMO, Al Alhendi AS, Al-Grad MSH, et al. Perceived stress, reasons for and sources of stress among medical students at Rabigh Medical College, King Abdulaziz University, Jeddah, Saudi Arabia. BMC Med Educ 2018; 18: 29.

16. Saeed AA, Bahnassy AA, Al-Hamdan NA, Almudhaibery FS, Alyahya AZ. Perceived stress and associated factors among medical students. J Family Community Med 2016; 23: 166-171.

17. Ezmeirlly HA, Farahat FM. Illness anxiety disorder and perception of disease and distress among medical students in western Saudi Arabia. Saudi Med J 2019; 40: 1144-1149.

18. AlFaris E, Irfan F, Qureshi R, Naeem N, Alshomrani A, Ponnamperuma G, et al. Health professions' students have an alarming prevalence of depressive symptoms: exploration of the associated factors. BMC Med Educ 2016; 16: 279.

19. Alshehri A, Azahrani H, Alotaibi M. Internet Addiction amon among Taif University Students and its ts Association with Psychiatric Co Morbidities. Merit Research Journal of Medicine and Medical Sciences 2015; 3: 536-544.

20. Alharbi H, Almalki A, Alabdan F, Haddad B. Depression among medical students in Saudi medical colleges: a crosssectional study. Adv Med Educ Pract 2018; 9: 887-891.

21. Safdar L, Shahbaz A, Chaudry S. A Comparative Study of Stress among Undergraduate Medical and Non-Medical Students. Journal of Rawalpindi Medical College 2018; 22: 77-80.

22. Abdel Rahman AG, Al Hashim BN, Al Hiji NK, Al-Abbad Z. Stress among medical Saudi students at College of Medicine, King Faisal University. J Prev Med Hyg 2013; 54: 195-199.

23. Iqbal S, Gupta S, Venkatarao E. Stress, anxiety and depression among medical undergraduate students and their sociodemographic correlates. Indian J Med Res. 2015; 141: 354-357.

24. Beiter R, Nash R, McCrady M, Rhoades D, Linscomb M, Clarahan $\mathrm{M}$, et al. The prevalence and correlates of depression, anxiety, and stress in a sample of college students. J Affect Disord 2015; 173: 90-96.

25. Lovibond SH, Lovibond PF, editors. Manual for the depression anxiety stress scales. Sydney: Psychology Foundation of Australia; 1996. 
26. Basudan S, Binanzan N, Alhassan A. Depression, anxiety and stress in dental students. Int J Med Educ 2017; 8: 179-186.

27. Lovibond PF, Lovibond SH. The structure of negative emotional states: comparison of the Depression Anxiety Stress Scales (DASS) with the Beck Depression and Anxiety Inventories. Behav Res Ther 1995; 33: 335-343.

28. Fawzy M, Hamed SA. Prevalence of psychological stress, depression and anxiety among medical students in Egypt. Psychiatry Res 2017; 255: 186-194.

29. Moussa MT, Lovibond P, Laube R, Megahead HA. Psychometric Properties of an Arabic Version of the Depression Anxiety Stress Scales (DASS). Research on Social Work Practice 2017; 27: 375-386.

30. Fayyaz NM, Beg R. Systematic Review and Meta-analysis of Major Depression and Suicidal Ideation among University Students in the Middle East. The Journal of Middle East and North Africa Sciences 2019; 5: 1-5.

31. Ibrahim N, Al-Kharboush D, El-Khatib L, Al-Habib A, Asali D. Prevalence and Predictors of Anxiety and Depression among Female Medical Students in King Abdulaziz University, Jeddah, Saudi Arabia. Iran J Public Health 2013; 42: 726-736.

32. Dyrbye LN, Thomas MR, Shanafelt TD. Systematic review of depression, anxiety, and other indicators of psychological distress among U.S. and Canadian medical students. Acad Med 2006; 81: 354-373.

33. Elani HW, Allison PJ, Kumar RA, Mancini L, Lambrou A, Bedos C. A systematic review of stress in dental students. J Dent Educ 2014; 78: 226-242.
34. Labrague LJ, McEnroe-Petitte DM, Gloe D, Thomas L, Papathanasiou IV, Tsaras K. A literature review on stress and coping strategies in nursing students. J Ment Health 2017; 26 : 471-480.

35. Bacchi S, Licinio J. Qualitative Literature Review of the Prevalence of Depression in Medical Students Compared to Students in Non-medical Degrees. Acad Psychiatry 2015; 39: 293-299.

36. Amarasuriya SD, Jorm AF, Reavley NJ. Perceptions and intentions relating to seeking help for depression among medical undergraduates in Sri Lanka: a cross-sectional comparison with non-medical undergraduates. BMC Med Educ 2015; 15: 162.

37. Rotenstein LS, Ramos MA, Torre M, Segal JB, Peluso MJ, Guille C, et al. Prevalence of Depression, Depressive Symptoms, and Suicidal Ideation Among Medical Students: A Systematic Review and Meta-Analysis. JAMA 2016; 316: 2214-2236.

38. Bhat US, Amaresha AC, Kodancha P, John S, Kumar S, Aiman A, et al. Psychological distress among college students of coastal district of Karnataka: A community-based cross-sectional survey. Asian J Psychiatr 2018; 38: 20-24.

39. Menon V, Sarkar S, Kumar S. Barriers to healthcare seeking among medical students: a cross sectional study from South India. Postgrad Med J 2015; 91: 477-482.

40. Yusoff MSB, Abdul Rahim AF, Yaacob MJ. Prevalence and Sources of Stress among Universiti Sains Malaysia Medical Students. Malays J Med Sci 2010; 17: 30-37.

\section{Clinical Practice Guidelines}

Clinical Practice Guidelines must include a short abstract. There should be an Introduction section addressing the objective in producing the guideline, what the guideline is about and who will benefit from the guideline. It should describe the population, conditions, health care setting and clinical management/diagnostic test. Authors should adequately describe the methods used to collect and analyze evidence, recommendations and validation. If it is adapted, authors should include the source, how, and why it is adapted? The guidelines should include not more than 50 references, 2-4 illustrations/tables, and an algorithm. 